\title{
Semicircular Canal Size and Locomotion in Colobine Monkeys: A Cautionary Tale
}

\author{
Todd C. Rae ${ }^{a}$ Paul Martin Johnson ${ }^{a}$ Wataru Yano $^{b}$ Eishi Hirasaki ${ }^{c}$ \\ ${ }^{a}$ Centre for Research in Evolutionary, Social and Inter-Disciplinary Anthropology, University \\ of Roehampton, London, UK; ${ }^{\mathrm{b}}$ Department of Oral Anatomy, Asahi University School of \\ Dentistry, Mizuho, and 'Primate Research Institute, Kyoto University, Inuyama, Japan
}

\author{
Key Words \\ Bony labyrinth $\cdot$ Inner ear morphology $\cdot$ Leaping $\cdot$ Balance $\cdot$ Colobus $\cdot$ Presbytis
}

\begin{abstract}
The semicircular canals of the inner ear constitute the organ of balance, tracking head rotation during movement and facilitating stabilisation of vision. Morphological characteristics of the canals are correlated with agility scores related to locomotion. To date, however, the relationship between canal morphology and specific locomotor behaviours, such as leaping, is unclear. Knowledge of such a relationship could strengthen the inferences of locomotion of extinct taxa. To test this, crania of two sets of closely related primate species (Presbytis melalophos and P. potenziani; Colobus guereza and C. polykomos) that differ in the percentage of leaping in their locomotor repertoire were examined using microscopic computed tomography. Three-dimensional virtual models of the bony labyrinth were derived, and the radius of curvature of each of the three canals was evaluated relative to cranial size. The findings are contradictory; one leaping form (P. melalophos) differs from its congener in possessing significantly larger lateral canals, a pattern seen in previous studies of primates, while the other leaper (C. guereza) has significantly smaller posterior canals than its close relative. These results undermine efforts to determine specific locomotor behaviours from the bony labyrinth of extinct primates.

(c) 2016 S. Karger AG, Basel
\end{abstract}

\section{Introduction}

Locomotor studies of primates focus primarily on the postcranial evidence [Su and Jablonski, 2009]. Hard and soft tissue characteristics generally associated with habitual locomotor modes are found in the limbs [Fleagle, 1976, 1977], although non-

\begin{tabular}{ll}
\hline KARGER & ๑ 2016 S. Karger AG, Basel \\
E-Mail karger@karger.com & $0015-5713 / 16 / 0874-0213 \$ 39.50 / 0$ \\
www.karger.com/fpr &
\end{tabular}

Todd C. Rae

Centre for Research in Evolutionary, Social and Inter-

Disciplinary Anthropology, Department of Life Sciences University of Roehampton

Holybourne Avenue, London SW15 4JD (UK)

E-Mail t.rae@ roehampton.ac.uk 


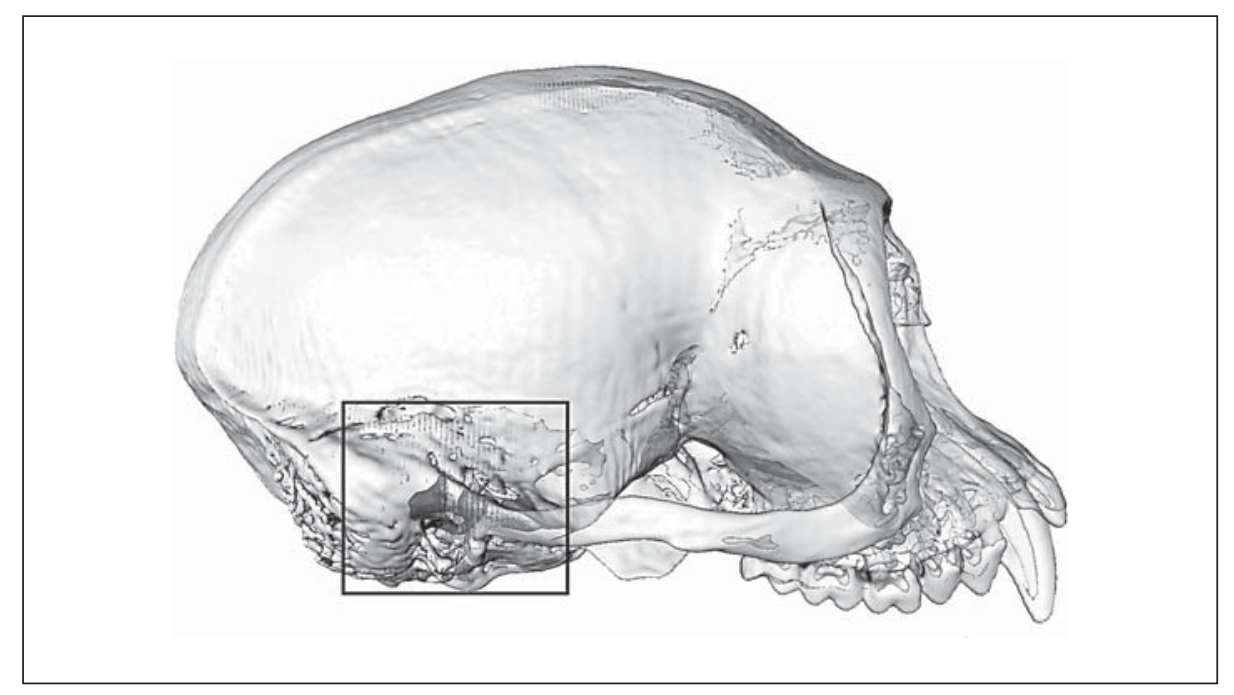

Fig. 1. Location of the bony labyrinth (shaded) in the temporal bone, seen in a 3-dimensional virtual reconstruction of a Presbytis cranium derived from microscopic computed tomographic scans and rendered semitransparent.

locomotor activity also affects the postcrania [Dunham et al., 2015]. More recently, however, the advent of modern imaging techniques has allowed the examination of the internal portions of the cranium, including the labyrinth of the temporal bone, which includes the organ of balance [Spoor and Zonneveld, 1998]. Exploration of the link between labyrinth morphology and motion has yielded substantial results, both within primates and among mammals more generally [Spoor et al., 2007; Welker et al., 2009; Billet et al., 2012; Pfaff et al., 2015].

The inner ear (fig. 1) is comprised of numerous connected cavities known as the osseous (or bony) labyrinth in mammals [Gray, 1908; Spoor and Zonneveld, 1995, 1998; Schmelzle et al., 2007; Welker et al., 2009; Billet et al., 2012; Gunz et al., 2012; Pfaff et al., 2015] and other vertebrates [Boistel et al., 2011]. The bony labyrinth consists of the cochlea, vestibule and semicircular canals [Sinnatamby, 2006], in which are contained the components of the membranous labyrinth: cochlear duct, the saclike utricle and saccule, and the semicircular ducts, respectively [Gray, 1908; Sinnatamby, 2006; Walker et al., 2008]. The cochlea houses the hearing system, while the vestibular system (vestibule and semicircular canals) forms the organ of balance. These systems reside within the otic capsule of the petrosal portion of the temporal bone [Lieberman, 2011].

The membranous labyrinth is smaller in diameter (lumen) than the enclosing osseous labyrinth, and is separated from the bony wall by a supporting fluid known as perilymph [Ekdale, 2013]. The membranous labyrinth contains fluid known as endolymph [Spoor, 2003; Sinnatamby, 2006], a heavy gelatinous fluid [Gibson, 1968] that responds to rotational acceleration of the head with a corresponding deflection, which in turn moves the hair-like cilia inside the semicircular ducts proportionally to 
Table 1. Percentage of leaping in the locomotor repertoire of Presbytis and Colobus

\begin{tabular}{lllc}
\hline Taxon & Leaping & $\begin{array}{l}\text { Quadruped- } \\
\text { alism }\end{array}$ & Other \\
\hline Presbytis melalophos* & 67.5 & 20.5 & 12 \\
Presbytis potenziani & 25 & 75 & 0 \\
Colobus guereza* & 38 & 41 & 21 \\
Colobus polykomos & 14.5 & 71.2 & 14.3 \\
\hline
\end{tabular}

Data derived from Fuentes [1996], Gebo and Chapman [1995], McGraw [1998] and Reed [1999]. For both genera, the species indicated by an asterisk leaps more than twice as frequently as its congener.

the force of the turn; the corresponding signal is transmitted to the brain via the vestibulocochlear nerve [Gibson, 1968; Mather, 2009]. The semicircular canals (and the ducts within them) are orientated in roughly orthogonal planes; thus, the brain interprets rotary head movement through a combination of input in three different axes: pitch, roll and yaw [Walker et al., 2008]. It is the membranous labyrinth that determines the crucial factors for balance sensitivity (e.g. size of the semicircular ducts), but as these variables are difficult or impossible to determine after death, characteristics of the bony canals alone are used in studies of the relationship between labyrinth morphology and locomotion [Spoor, 2003].

At a relatively wide scale, placental mammal species that move in ways that include quicker and more active actions require changes in the semicircular canals of the inner ear to cope with the more extensive head movement these taxa experience [Spoor et al., 2007; Ryan et al., 2012]. This mammalian pattern has been proposed for primates, as well; for example, forms that habitually leap (e.g. galagos, tarsiers) are reported to have relatively large semicircular canals, especially the lateral [Spoor et al., 2007]. For this finding to be operationalised with respect to fossil taxa, however, it is necessary to demonstrate that similar and/or closely related taxa that differ in locomotor pattern also differ significantly in bony labyrinth morphology, particularly as some extant primates have been shown to deviate from expectation [Spoor et al., 2007]. The hypothesis that Colobus possesses larger canals than Procolobus because the former leaps more frequently [Walker et al., 2008] is taken as the starting point of the present investigation.

To test the prediction that closely related colobines differ in their semicircular canal morphology due to differences in the percentage of travel time spent leaping, an important part of the typical colobine locomotor repertoire [Davison, 1982], two members of the genus Colobus (C. polykomos and C. guereza) and the genus Presbytis (P. melalophos and P. potenziani) that differ in the percentage of leaping in their overall locomotor repertoire (table 1) are examined here. To support the hypothesis that larger canals are associated with leaping, it is expected that both species pairs will show the same relationship (i.e. the leaping form in each genus will have larger canals than its congener).

All 4 of the taxa examined here are medium-sized (6-13 kg) arboreal monkeys with a high percentage of leaves in the diet [Rowe, 1996; Fleagle, 1999]. P. melalophos 
Fig. 2. Three-dimensional virtual reconstruction of the bony labyrinth of Presbytis. The semicircular canals are orientated orthogonally to one another for sensing pitch, roll and yaw of the head. Scale bar $=1 \mathrm{~mm}$.

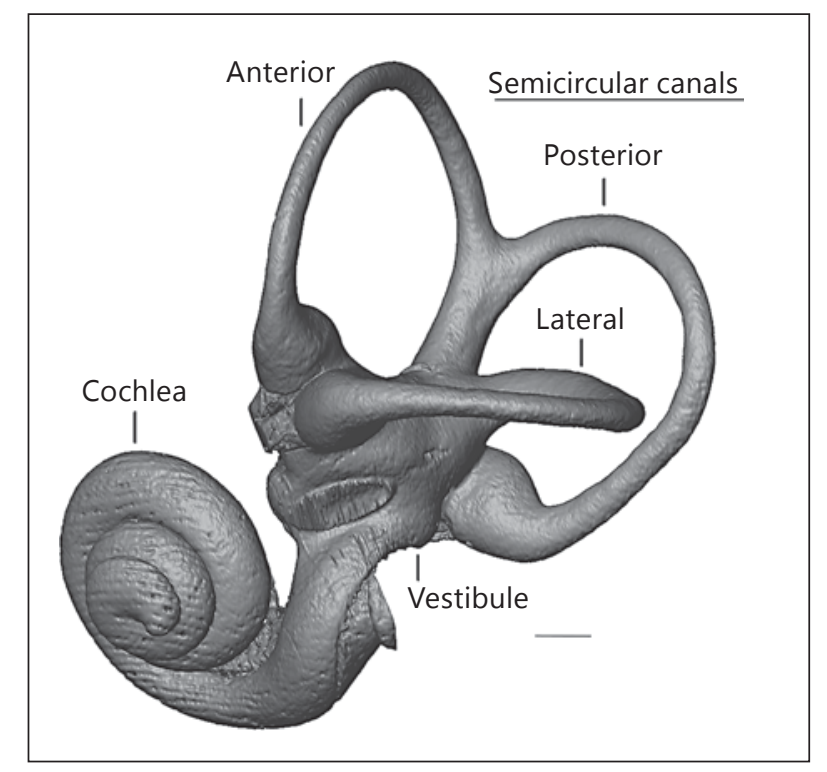

and $P$. potenziani live on the south-east Asian islands of Sumatra and Mentawai, respectively, although P. melalophos is also found on the mainland of the Malay Peninsula [Fleagle, 1999]. The difference in their degree of leaping behaviour is not obviously related to their habitats, as both species inhabit primary and secondary forests [Rowe, 1996]. C. polykomos and C. guereza are larger and more dimorphic than the Asian forms, and live in the western and central/eastern regions of the central African rain forest, respectively [Fleagle, 1999]. The percentage of travel time spent leaping differs between them perhaps because C. polykomos lives primarily in continuous, primary forest, while C. guereza frequents more secondary forest and wooded grassland [Rowe, 1996], where leaping between supports is more likely to be necessary.

Phylogenetically, Colobus and Presbytis are both members of the Colobinae, but belong to separate branches of the subfamily; Presbytis is more closely related to the 'odd-nosed' colobines (Nasalis, Rhinopithecus, Pygathrix), while Colobus is part of a monophyletic African clade with Piliocolobus [Wang et al., 2012]. In both cases, the species examined here are very closely related to their congeners, sharing a common ancestor with only 1 other species ( $P$. comata and C. vellerosus, respectively), aside from each other [Ting, 2008; Meyer et al., 2011].

The decision to examine congeners was taken to diminish the effect of extraneous variables on the ensuing comparisons; this can be useful for detecting adaptive responses [Crews, 1997]. Species pairs form natural experiments from which behaviours can be linked to morphology [Fleagle, 1976, 1977; Katz and Harris-Warrick, 1999]. For example, comparing closely related taxa has the effect of reducing the influence of phylogeny so that those differences of interest (in this case, frequency of leaping) can be examined in relative isolation [Birkhead et al., 1992]. Using two different species pairs eliminates many of the inherent problems [Garland and Adolf, 1994] with standard 2-species comparisons. 
Fig. 3. Height (h) and width (w) measurements used to calculate the canal radius $\mathrm{R}$. Scale bar $=1 \mathrm{~mm}$.

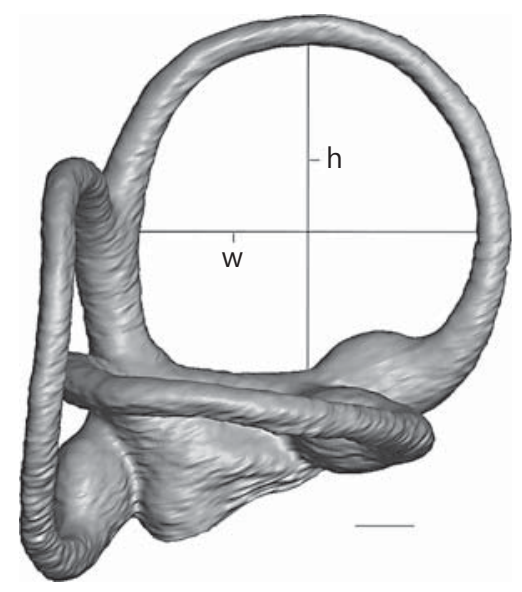

\section{Materials and Methods}

A mixed-sex sample of wild-shot, adult dry crania of P. melalophos $(\mathrm{n}=5)$ and P. potenziani $(\mathrm{n}=4)$ from the collection of the Primate Research Institute of Kyoto University, Inuyama, Japan, and of C. polykomos $(\mathrm{n}=6)$ and C. guereza $(\mathrm{n}=6)$ from the Natural History Museum, London, UK, was examined. Colobus individuals were scanned at Hull York Medical School using an X-TEK HMX160 high-resolution computed tomography scanner (X-Tek Systems, Tring, $\mathrm{UK})$, with no additional filters applied. All scans were taken at $75 \mathrm{kV}$ and $30 \mu \mathrm{A}$. Voxel size was specimen dependent, but was $\leq 0.04 \mathrm{~mm}$ in all cases. Presbytis scan sets were obtained at the Asahi University School of Dentistry, Japan, using a Scan-Xmate-RB090SS (Comscan Tecno, Sagamihara, Japan). All scans were acquired at $80-90 \mathrm{kV}$ and $90-100 \mu \mathrm{A}$, with a voxel size $\leq 0.04$ $\mathrm{mm}$.

Semicircular canal parameters were determined using a modified version [Schmelzle et al., 2007] of the methods outlined in Spoor et al. [2007]. Virtual 3-dimensional models of the labyrinth (fig. 2) were constructed via manual segmentation in Avizo version 8 (Visualization Sciences Group, Burlington, Mass., USA). Although other parameters of vestibular morphology have been investigated [Pfaff et al., 2015; Grohé et al., 2016], the present study focuses on the radius of curvature (R) as a measure of canal size [Schmelzle et al., 2007]. $R$ is derived from internal height and width measurements: height is measured from the protrusion of the ampulla at the lowest point of the canal to its maximum possible extent on the canal opposite, width was then determined as the maximum length line intersecting the height line at $90^{\circ}$ (fig. 3 ). $\mathrm{R}$ is calculated as $0.5 \times[$ (height + width $) / 2]$.

To scale for size, values for each canal were derived by dividing $\mathrm{R}$ by the cranial body mass proxy, prosthion-inion cranial length [Martin and Ross, 2005]; previous work [Johnson, 2012] on Colobus shows that similar results are obtained using other canal variables and scalars (area beneath the canal and $\mathrm{M}^{1}$ area, respectively). Ratio-based methods of scaling work best when an isometric relationship exists between the variable and the scalar; this was tested by determining the $95 \%$ confidence intervals of the slopes of linear regressions of $\mathrm{R}$ onto prosthion-inion length. The resulting data were analysed for normality using a 1-sample Kolmogorov-Smirnov test, then by independent samples t tests. All statistics were performed using IBM SPSS version 21 (IBM Corp., Armonk, N.Y., USA) with $\alpha=0.05$ for significance. 


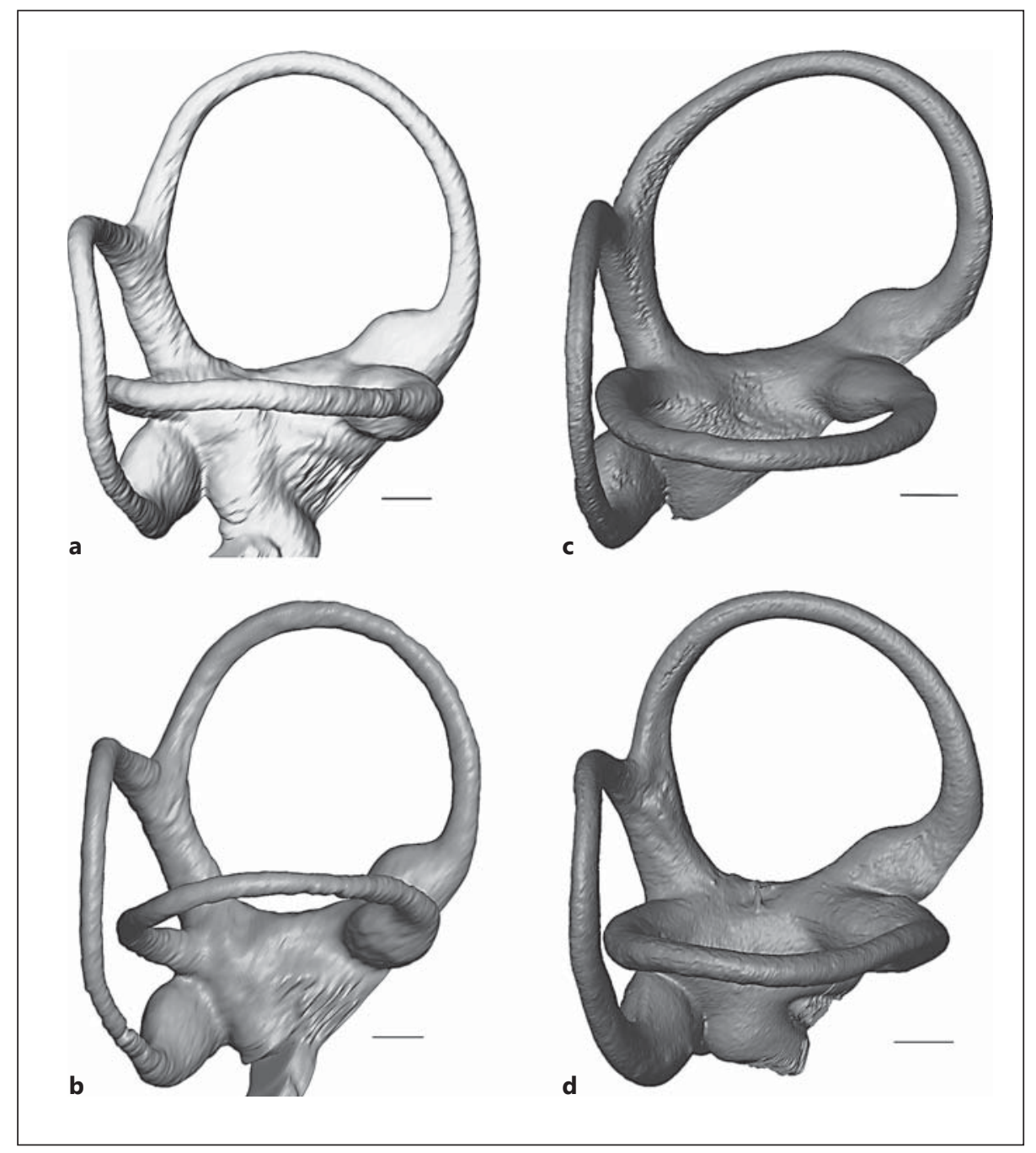

Fig. 4. Virtual canals of C. guereza (a), C. polykomos (reversed; b), P. melalophos (c) and P. potenziani $(\mathbf{d})$. Scale bars $=1 \mathrm{~mm}$.

\section{Results}

Examples of the virtual reconstructions of the canals are shown in figure 4 . The mean values of $\mathrm{R}$ and cranial length are given in table 2 . The $95 \%$ confidence intervals of the regression slopes of $\mathrm{R}$ against size included isometry except in the case of the anterior canal, where the lower confidence interval approached isometry. No samples of $\mathrm{R}$ for which $\mathrm{n}>5$ differed significantly from normality (the small sample of $P$. potenziani precluded analysis). 
Table 2. Species means for anterior, posterior and lateral canal radius $\mathrm{R}(\mathrm{mm})$ and the cranial size proxy (prosthion-inion length; $\mathrm{mm})$

\begin{tabular}{lllllr}
\hline Taxon & $\mathrm{n}$ & Anterior & Posterior & Lateral & Size \\
\hline Presbytis melalophos & 5 & 2.24 & 2.23 & 2.34 & 98.62 \\
Presbytis potenziani & 4 & 2.26 & 2.00 & 1.97 & 92.98 \\
Colobus guereza & 6 & 2.66 & 2.32 & 2.22 & 112.96 \\
Colobus polykomos & 6 & 2.61 & 2.48 & 2.28 & 109.28 \\
\hline
\end{tabular}

Neither species pair differed significantly in size-corrected $\mathrm{R}$ for anterior canals (fig. 5). In Presbytis, however, the species that leaps more frequently (P. melalophos) shows significantly larger lateral canals, with $t=2.867$, d.f. $=7$, sig. (2-tailed) $=0.024$. The results for Colobus, however, show an entirely different pattern; the leaping form (C. guereza) has both anterior and lateral canals that are statistically indistinguishable from its congener, but possesses posterior canals that are significantly smaller, with $\mathrm{t}=-2.656$, d.f. $=10$, sig. (2-tailed) $=0.024$ (fig. 5).

\section{Discussion}

In Presbytis, the difference (larger lateral canals) between species that vary widely in the amount they leap during locomotion is in the same canal and in the same direction as that reported for other primates [Spoor et al., 2007]. Combined with the fact that this statistically significant difference is found even at relatively small sample sizes $(n=4-6)$, this could be construed as support for previous interpretations. The fact that Colobus species show a completely different pattern (the leaping form has smaller posterior canals), however, suggests that caution should be exercised when attempting to use the Presbytis results on their own to infer behaviour in extinct forms.

The failure of primate congeners that differ in specifics in the locomotor repertoire to show a consistent pattern in semicircular canal size suggests that either (a) leaping reflects a sufficiently different aspect of locomotor function from the multivariate agility categories utilised previously that the morphological signals in the organ of balance are not comparable, (b) increasing the amount of leaping in the locomotor repertoire by over $100 \%$ has no effect on labyrinth morphology, or (c) the influence of drift at the lower taxonomic level examined here is greater than any inferred functional adaptation. A fourth possibility is that the method used to take body size differences into account may have introduced an allometric effect; however, the fact that the size of the two canals for which significant differences exist scale against cranial length in a manner indistinguishable from isometry makes this unlikely. Precisely which of these possibilities is most probable is unclear at present.

Even though it had been suggested previously [Spoor et al., 2007; Walker et al., 2008] that leaping may have a critical effect on the organ of balance, the differences between the broad behavioural categories of agility used in more wide-ranging studies on the one hand and specifically leaping on the other may be sufficient to result in distinct patterns of labyrinthine morphology. As the agility scores used in previous research [Spoor et al., 2007] include speed (and, presumably, additional attributes of 
Fig. 5. Box-and-whisker plots of size-adjusted R of Presbytis (a) and Colobus (b) semicircular canals. The anterior, posterior and lateral canals are indicated below each chart. The species that leaps more frequently is indicated by the monkey symbol.

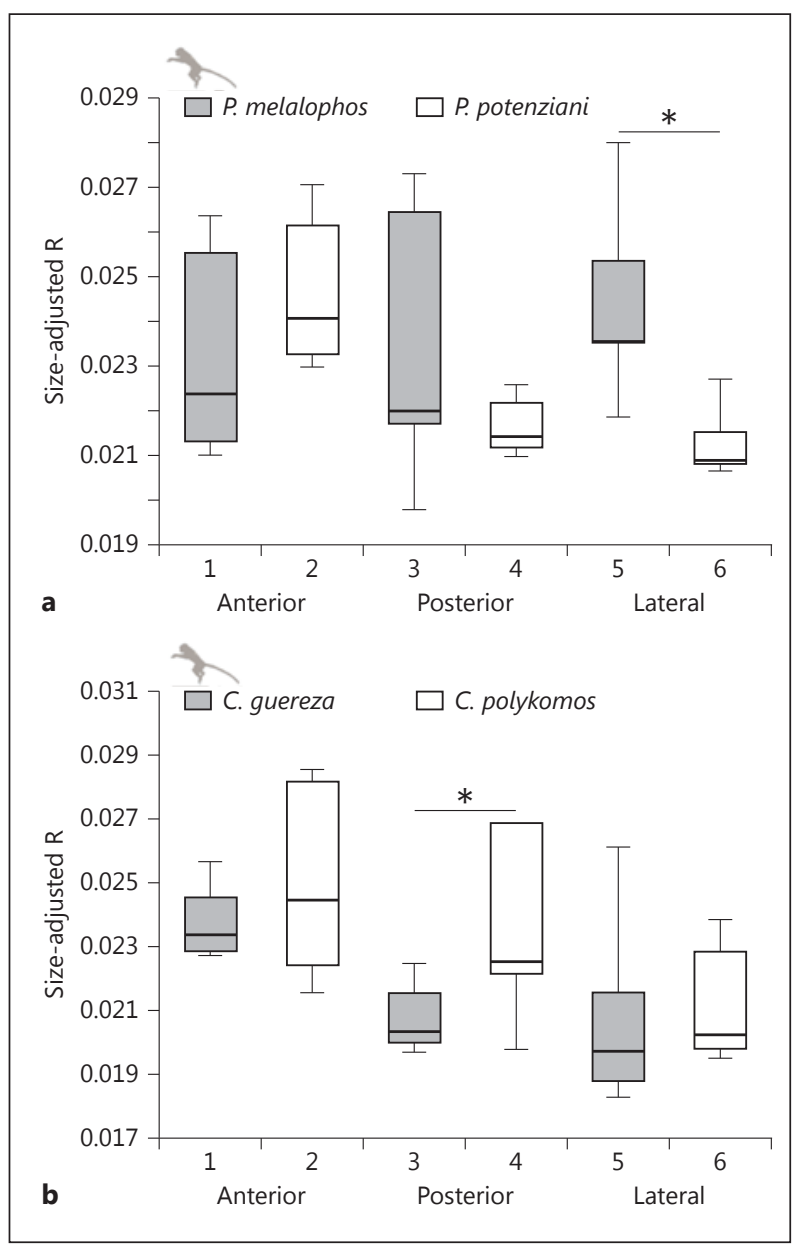

locomotor behaviour), it may be that these factors (rather than percentage of leaping) have affected the results. Indeed, although the larger lateral canals of tarsiers have been linked explicitly to their leaping behaviour [Spoor et al., 2007], they have also been suggested to be the result of the increased degree of head rotation associated with their vertical clinging and leaping mode of movement [Spoor and Zonneveld, 1998]. If this is the case, leaping may not be a sufficiently powerful selective pressure to affect the organ of balance substantially, in which case other explanations for the significant results obtained above are necessary.

It could also be argued that the amount of difference between taxa in terms of the percentage of leaping in the locomotor repertoire recorded here (over 100\% in both cases) is insufficient to affect the organ of balance. If so, then the labyrinth differs from other anatomical systems (e.g. skeletal and muscular [Fleagle, 1976, 1977]) that demonstrate just such a variation within the same subfamily; indeed, for 1 case, in the same genus. Again, however, the contradictory nature of the results compli- 
cates the interpretation, as the significant results suggest that some effect is present, but in two different directions on two different canals. It has also been demonstrated that a substantial amount of phylogenetic signal may be present in the labyrinthine morphology of some primate groups [Lebrun et al., 2010], which could affect the results, although the use of congeneric pairs reduces the likelihood that this is a significant factor. In addition, because behavioural flexibility is a characteristic of primates, and because behaviour can change more quickly than morphology, evolutionary lag might be invoked [Blomberg et al., 2003], although it would not fully account for the conflicting significant differences.

A final potential interpretation is that the differences seen are the result of genetic drift. If this is the case, it would imply that chance affects labyrinth morphology to a greater extent than forces produced during locomotion. In some ways, drift is (and perhaps should be) the null explanation for differences between closely related taxa (or, indeed, individuals), a notion that has been receiving more attention recently [Weaver et al., 2007; Betti et al., 2010]. Additional testing would be required to see whether the pattern of the variation in semicircular canal radius in colobines is distinguishable from those derived from drift models; if not, no functional explanation for the observed differences would be necessary. Alternatively, it may be that a multivariate approach [Gunz et al., 2012] is needed to differentiate between taxa such as those investigated here, although this may limit the extent to which individual traits of the labyrinth can be subjected to statistical testing. In any event, the fact that these significant patterns are diametrically opposed in two sets of closely related taxa reduces the confidence that can be placed on inferences derived from comparisons between fossil and living taxa.

\section{Acknowledgements}

The authors acknowledge financial support provided via a Primate Society of Great Britain grant awarded to P.M.J. and a Japan Society for the Promotion of Science Fellowship awarded to T.C.R. Permission to study the Natural History Museum material was facilitated by Roberto Portela Miguez. Scanning at Hull York Medical School was generously provided by Paul O'Higgins and Michael J. Fagan, and performed by Sue Taft. The manuscript was improved by comments from the Editor and an anonymous reviewer.

\section{References}

Betti L, Balloux F, Hanihara T, Manica A (2010). The relative role of drift and selection in shaping the human skull. American Journal of Physical Anthropology 141: 76-82.

Billet G, Hautier L, Asher RJ, Schwarz C, Crumpton N, Martin T, Ruf I (2012). High morphological variation of vestibular system accompanies slow and infrequent locomotion in three-toed sloths. Proceedings of the Royal Society B 279: 3932-3939.

Birkhead TR, Clarkson K, Reynolds MD, Koenig WD (1992). Copulation and mate guarding in the yellowbilled magpie Pica nuttalli and a comparison with the black-billed magpie P. pica. Behaviour 121: $110-130$.

Blomberg SP, Garland T, Ives AR (2003). Testing for phylogenetic signal in comparative data: behavioral traits are more labile. Evolution 57: 717-745.

Boistel R, Herrel A, Lebrun R, Daghfous G, Tafforeau P, Losos JB, Vanhooydonck B (2011). Shake rattle and roll: the bony labyrinth and aerial descent in squamates. Integrative and Comparative Biology 51: 957-968. 
Crews D (1997). Species diversity and the evolution of behavioral controlling mechanisms. Annals of the New York Academy of Sciences 807: 1-21.

Davison GWH (1982). Convergence with terrestrial cercopithecines by the monkey Rhinopithecus roxellanae. Folia Primatologica 37: 209-215.

Dunham NT, Kane EE, McGraw WS (2015). Scapular morphology and forelimb use during foraging in four sympatric cercopithecids. Folia Primatologica 86: 474-489.

Ekdale EG (2013). Comparative anatomy of the bony labyrinth (inner ear) of placental mammals. PLoS One 8: e66624.

Fleagle JG (1976). Locomotor behavior and skeletal anatomy of sympatric Malaysian leaf-monkeys (Presbytis obscura and Presbytis melalophos). Yearbook of Physical Anthropology 20: 440-453.

Fleagle JG (1977). Locomotor behavior and muscular anatomy of sympatric Malaysian leaf-monkeys (Presbytis obscura and Presbytis melalophos). American Journal of Physical Anthropology 46: 297308.

Fleagle JG (1999). Primate Adaptation and Evolution, 2nd ed. San Diego, Academic Press.

Fuentes A (1996). Feeding and ranging in the Mentawai Island langur (Presbytis potenziani). International Journal of Primatology 17: 525-548.

Garland T, Adolph S (1994). Why not to do two-species comparative studies: limitations on inferring adaptation. Physiological Zoology 67: 797-828.

Gebo DL, Chapman CA (1995). Positional behavior in five sympatric Old World monkeys. American Journal of Physical Anthropology 97: 49-76.

Gibson JJ (1968). The Senses Considered as Perceptual Systems. London, Allen \& Unwin.

Gray AA (1908). An investigation on the anatomical structure and relationships of the labyrinth in the reptile, the bird, and the mammal. Proceedings of the Royal Society B 80: 507-528.

Grohé C, Tseng J, Lebrun R, Boistel R, Flynn JJ (2016). Bony labyrinth shape variation in extant Carnivora: a case study of Musteloidea. Journal of Anatomy 228: 366-383.

Gunz P, Ramsier M, Kuhrig M, Hublin J-J, Spoor F (2012). The mammalian bony labyrinth reconsidered, introducing a comprehensive geometric morphometric approach. Journal of Anatomy 220: 529543.

Johnson PM (2012). Leaping in the Ears? A Test of the Semicircular Canals as Locomotor Indicators in Closely Related Primate Taxa. MRes thesis, University of Roehampton.

Katz PS, Harris-Warrick RM (1999). The evolution of neuronal circuits underlying species-specific behaviour. Current Opinion in Neurobiology 9: 628-633.

Lebrun R, de Leon MP, Tafforeau P, Zollikofer C (2010). Deep evolutionary roots of strepsirrhine primate labyrinthine morphology. Journal of Anatomy 216: 368-380.

Lieberman DE (2011). The Evolution of the Human Head. Harvard, Harvard University Press.

Martin RD, Ross CF (2005). The evolutionary and ecological context of primate vision. In The Primate Visual System: A Comparative Approach (Kremers J, ed.), pp 1-36. Chichester, Wiley \& Sons.

Mather G (2009). Foundations of Sensation and Perception. Hove, Psychology Press.

McGraw WS (1998). Comparative locomotion and habitat use of six monkeys in the Tai Forest, Ivory Coast. American Journal of Physical Anthropology 105: 493-510.

Meyer D, Rinaldi ID, Ramlee H, Perwitasari-Farajallah D, Hodges JK, Roos C (2011). Mitochondrial phylogeny of leaf monkeys (genus Presbytis, Eschscholtz, 1821) with implications for taxonomy and conservation. Molecular Phylogenetics and Evolution 59: 311-319.

Pfaff C, Martin T, Ruf I (2015). Bony labyrinth morphometry indicates locomotor adaptations in the squirrel-related clade (Rodentia, Mammalia). Proceedings of the Royal Society B 282: 20150744.

Reed K (1999). Population density of primates in communities: differences in community structure. In Primate Communities (Fleagle JG, Janson C, Reed KE, eds.), pp 116-140. Cambridge, Cambridge University Press.

Rowe N (1996). The Pictorial Guide to the Living Primates. East Hampton, Pogonias Press.

Ryan TM, Silcox MT, Walker A, Mao X, Begun DR, Benefit BR, Gingerich PD, Köhler M, Kordos L, McCrossin ML, Moyà-Solà S, Sanders WJ, Seiffert ER, Simons E, Zalmout IS, Spoor F (2012). Evolution of locomotion in Anthropoidea: the semicircular canal evidence. Proceedings of the Royal Society $B$ 279: 3467-3475.

Schmelzle T, Maier W, Sánchez-Villagra MR (2007). Vestibular labyrinth evolution in diprotodontian marsupial mammals. Mammal Study 32: 83-97.

Sinnatamby CS (2006). Last's Anatomy: Regional and Applied, 11th ed. Edinburgh, Churchill Livingstone. Spoor F (2003). The semicircular canal system and locomotor behaviour, with special reference to hominin evolution. Courier Forschungsinstitut Senckenberg 243: 93-104.

Spoor F, Zonneveld F (1995). Morphometry of the primate bony labyrinth: a new method based on highresolution computed tomography. Journal of Anatomy 186: 271-286.

Spoor F, Zonneveld F (1998). Comparative review of the human bony labyrinth. Yearbook of Physical Anthropology 27: 211-251. 
Spoor F, Garland T Jr, Krovitz G, Ryan TM, Silcox MT, Walker A (2007). The primate semicircular canal system and locomotion. Proceedings of the National Academy of Sciences of the United States of America 104: 10808-10812.

Su DF, Jablonski NG (2009). Locomotor behavior and skeletal morphology of the odd-nosed monkeys. Folia Primatologica 80: 189-219.

Ting N (2008). Mitochondrial relationships and divergence dates of the African colobines: evidence of Miocene origins for the living colobus monkeys. Journal of Human Evolution 55: 312-325.

Walker A, Ryan TM, Silcox MT, Simons E, Spoor F (2008). The semicircular canal system and locomotion: the case of extinct lemuroids and lorisoids. Evolutionary Anthropology 17: 135-145.

Wang XP, Yu L, Roos C, Ting N, Chen CP, Wang J, Zhang YP (2012). Phylogenetic relationships among the colobine monkeys revisited: new insights from analyses of complete $\mathrm{mt}$ genomes and 44 nuclear non-coding markers. PLoS One 7: e36274.

Weaver T, Roseman C, Stringer C (2007). Were Neandertal and modern human cranial differences produced by natural selection or genetic drift? Journal of Human Evolution 53: 135-145.

Welker KL, Orkin JD, Ryan TM (2009). Analysis of intraindividual and intraspecific variation in semicircular canal dimensions using high-resolution X-ray computed tomography. Journal of Anatomy 215: 444-451. 